\title{
Úlceras leishmanióticas cutâneas com presença de Corynebacterium diphtheriae
}

\author{
Cutaneousleishmaniotic ulcers with Corynebacterium diphtheriae
}

\author{
Luis Angel Vera', Vanize de Oliveira Macêdo', Albino Verçosa de Magalhães², \\ Isolina Allen Ciuffo ${ }^{3}$, Conceição Guerra Santos ${ }^{3}$ e João Barberino Santos ${ }^{1}$
}

Resumo Em um estudo prospectivo para avaliar a influência da infecção bacteriana secundária na evolução da leishmaniose cutânea, em Corte de Pedra (Bahia), obteve-se o isolamento de Corynebacterium diphtheriae em $7(8,3 \%)$ de 84 pacientes portadores de úlceras, avaliados. Devido ao pequeno número de pacientes com a presença da bactéria na úlcera, não foi possível concluir se Corynebacterium diphtheriae comporta-se apenas como colonizante, nem sobre a sua influência no processo de cicatrização da úlcera leishmaniótica.

Palavras-chaves: Leismaniose tegumentar. Úlcera. Infecção bacteriana. Corynebacterium diphtheriae.

Abstract In a prospective study to evaluate the influence of secondary bacterial infection on the evaluation of cutaneous leishmaniasis, in Corte de Pedra (Bahia), we isolated Corynebacterium diphtheriae in 7 (8.3\%) out of 84 patients with ulcers studied. Due to the small number of patients with the presence of the bacteria in the ulcer, we could not conclude whether Corynebacterium diphtheriae behaves only as a colonizer nor its influence on the healing of the leishmaniotic ulcer.

Key-words: Tegumentary leishmaniasis. Ulcer. Infection. Corynebacterium diphtheriae.

Existem poucos relatos na literatura sobre a presença de corinebactérias patogênicas nas úlceras cutâneas leishmanióticas ${ }^{512}$. No Brasil, na região de Três Braços, BA, em 1986, foi isolado Corynebacterium diphtheriae em $56 \%$ das lesões de 16 pacientes com leishmaniose cutânea ${ }^{5}$. A influência

\section{PACIENTES E MÉTODOS}

Estudo prospectivo, de acompanhamento da mesma coorte pertencente a um estudo maior de avaliação de infecções bacterianas secundárias de úlceras leishmanióticas, realizado em Corte de Pedra (Bahia), entre agosto e dezembro de 1998. A metodologia empregada já foi descrita ${ }^{12}$, exceto os processos de isolamento e caracterização de Corynebacterium diphtheriae que foram aplicados.

Pesquisa de Corynebacterium diphtheriae. À admissão, de cada paciente foi obtida uma amostra da secreção da úlcera leishmaniótica mais antiga, mediante swab da parte interna da borda da lesão, e inoculada da bactéria no processo de cicatrização da úlcera leishmaniótica ainda não está definida. Neste estudo, procurou-se verificar a prevalência de Corynebacterium diphtheriae na leishmaniose cutânea e estudar sua relação com a reepitelização completa das úlceras.

em meio específico de Pai (ovo coagulado). O meio foi mantido à temperatura ambiente $\left( \pm 27^{\circ} \mathrm{C}\right)$ e transportado dentro das 24 horas seguintes para o LACEN-BA ${ }^{9}$, onde foi incubado aerobicamente a $35^{\circ} \mathrm{C}$, por um período de 24 horas. Posteriormente, a semeadura em placas contendo ágar sangue de carneiro a $5 \%$ e ágar chocolate telurito, permitiu o isolamento de colônias suspeitas e que foram caracterizadas através de testes bioquímicos (pesquisa da fermentação da glicose, maltose e hidrólise da uréia) e, posteriormente, à verificação da produção de exotoxina, recorrendo-se ao método de Elek ${ }^{4}$.

\footnotetext{
1. Núcleo de Medicina Tropical da Universidade de Brasília. 2. Laboratório de Patologia da Universidade de Brasília, Brasília, DF. 3. Laboratório Central (LACEN) de Salvador, Bahia, Brasil.

Endereço para correspondência: Dr. João Barberino Santos. Núcleo de Medicina Tropical/UNB, Campus Universitário, Caixa Postal 4517, $70910-970$ Brasília, DF.

Tel: 5561 273-5008, Fax: $5561273-2811$

e-mail: tropical@unb.br

Recebido para publicação em 5/10/2001.
} 


\section{RESULTADOS}

Foram estudados 84 pacientes com leishmaniose cutânea. As características epidemiológicas e clínicas dos pacientes incluidos neste estudo já foram relatadas anteriormente ${ }^{12}$.

Presença de Corynebacterium diphtheriae. Obteve-se o isolamento de $C$. diphtheriae em 7 (8,3\%) pacientes dos 84 portadores de úlceras que foram avaliados. Salienta-se que somente uma amostra bacteriana foi toxinogênica.

A idade dos 7 pacientes variou entre 4 e 41 anos, com média de 19,7 e com predominância do sexo masculino (57,1\%). Em 71,4\% houve o antecedente de vacinação DPT (difteria, tétano e coqueluche). As úlceras estavam localizadas nas pernas e pés em $57,1 \%$; nas coxas, em $14,3 \%$; e nos membros superiores, em $28,6 \%$.

Um mês após o final da terapia antimonial, foi avaliada a influência de Corynebacterium diphtheriae no processo de cicatrização. A reepitelização completa ocorreu em $57,1 \%$ nos 7 pacientes com presença anterior de $C$. diphtheriae nas úlceras, em comparação com $75 \%$ das 72 lesões sem evidência dessa bactéria, embora sem significância estatística: Risco Relativo = $1,71($ IC $95 \%=0,67-4,41) ; p=0,375$ para $a=0,05$ no Teste exato de Fisher.

\section{DISCUSSÃO}

O achado de $C$. diphtheriae em $8,3 \%$ dos 84 pacientes do estudo foi menor que a taxa de $56 \%$ encontrada em 16 pacientes leishmanióticos procedentes de Três Braços, em 1986, embora as percentagens de cepas toxinogênicas sejam semelhantes nos dois estudos, 14 e $11 \%$, respectivamente ${ }^{5}$. Essas diferenças podem ter sido causadas pelos critérios de seleção dos pacientes ou pelos procedimentos de transporte e isolamento empregados. As lesões estudadas não apresentaram base necrótica nem pseudomembrana, e nenhum paciente apresentou febre, conjuntivite ou evidência clínica de neurite. Estas últimas complicações, referidas na difteria cutânea, são muito raras ${ }^{278}$. Sabe-se que a pele lesada é um importante reservatório de C. diphtheriae, constituíndo-se as crianças o grupo de maior risco, especialmente nas áreas rurais das regiões tropicais ${ }^{10}$. Em um estudo feito no Rio de Janeiro, em 634 escolares com lesões cutâneas diversas e sem sinais sistêmicos de infecção, encontrou-se 122 (19\%) crianças portadoras da bactéria, sendo que em 10 (8\%) tinha característica toxinogênica ${ }^{3}$.

Em outros tipos de úlceras, como as produzidas nas pernas como complicação da falcemia, tem sido documentada a presença de $C$. diphtheriae em $10 \%$ de 80 pacientes, sendo a metade das espécies toxinogênicas ${ }^{11}$. Como parte do mesmo estudo, encontrou-se C. diphtheriae em 13 de 90 pacientes avaliados mais de uma vez, sem evidenciar presença de pseudomembrana local ou toxicidade sistêmica, embora 9 das 13 amostras de bactérias isoladas foram toxinogênicas ${ }^{1}$.

Em 790 militares combatentes nas ilhas do Pacífico Sul e Central na Segunda Guerra Mundial, encontrou-se
C. diphtheriae em $22 \%$ das úlceras cutâneas adquiridas nessas regiões tropicais, predominando as cepas toxinogênicas nas lesões precoces e, na maioria (75\%) das vezes, nas lesões múltiplas. Houve presença ocasional de neurite mas, geralmente, não se observou sintomas gerais de intoxicação. $\mathrm{O}$ achado de linfadenite foi raro $(1 \%)^{10}$.

A imunização oferece pouca proteção para o estado de portador de $C$. diphtheriae, mas deve-se administrar o toxóide. A antitoxina é potencialmente tóxica e não tem nenhum papel na terapia de portadores assintomáticos. O uso tópico de penicilina tem sido útil, mas pode mudar a composição da flora bacteriana para Gram negativos. O cuidado local com manutenção da área úmida também ajuda o tratamento ${ }^{10}$. A terapia consiste em penicilina $G$ benzatina 1,2 milhões de unidades IM, em dose única. A má higiene correlaciona com disseminação da difteria ${ }^{9}$. A natureza transitória do estado de portador tem sido demonstrada ${ }^{1}$. Não está claro se $C$. diphtheriae pode comportar-se somente como colonizante ${ }^{6}$.

Devido ao pequeno número de pacientes estudados (7 casos), não foi possível concluir sobre a influência de C. diphtheriae no processo de cicatrização das úlceras leishmanióticas. Há necessidade de mais estudos que permitam conclusões definitivas sobre essa influência, e também para verificar se há ação bacteriostática ou bactericida do antimonial sobre a bactéria. Nos estudos anteriores não foi avaliada a influência da bactéria neste processo. Em úlceras crônicas presentes nas pernas de pacientes com falcemia, tem-se observado a natureza transitória de $C$. diphtheriae, em torno de $60 \%$ dos pacientes avaliados ${ }^{1}$.

\section{REFERÊNCIAS BIBLIOGRÁFICAS}

1. Baum KF, Mac Farlane DE, Cupidore L, Serjeant GR Corynebacterium diphtheriae in sickle cell leg ulcers in Jamaica. West Indian Medical Journal 34: 24-28, 1985.

2. Black JA. Tropical ulcers and diphtheria. Journal of the Royal Society of Medicine 91: 60, 1998.
3. Formiga LCD. Difteria. Enfoque microbiológico-epidemiológico. Importância das lesões cutâneas e novas possibilidades de diagnóstico. Anais Brasileiros de Dermatologia 60: 337-338, 1985.

4. Formiga LCD. Diagnóstico microbiológico da difteria. Revista Brasileira de Patologia Clínica 22: 90-93, 1986. 
5. Formiga LCD, Assis ACB, Rangel LBA, Camello TCF, Suassuna I, Netto EM, Marsden PD. Isolamento de Corynebacterium diphtheriae de úlceras cutâneo-mucosas por Leishmania. Revista Brasileira de Patologia Clínica 22: 202-204, 1986.

6. Formiga LCD, Guaraldi AL. Diphtheria: current status and laboratory procedures for diagnosis. Revista Brasileira de Patologia Clínica 29: 93-96, 1993.

7. Frankland AW. Tropical ulcers and diphtheria. Journal of the Royal Society of Medicine 91: 174, 1998.

8. González-Ruiz A, Newsholme WA, Tan GD, Bryceson A, Ridgway GL. Tropical ulcers and diphtheria. Journal of the Royal Society of Medicine 90: 631-632, 1997.
9. Koopman JS, Campbell J. The role of cutaneous diphtheria infections in a diphtheria epidemic. The Journal of Infectious Diseases 131: 239-244, 1975.

10. Liebow AA, Mac Lean PD, Bumstead JH, Welt LG. Tropical ulcers and cutaneous diphtheria. Archives of Internal Medicine 78: 255295, 1946.

11. MacFarlane DE, Baum KF, Serjeant GR. Bacteriology of sickle cell leg ulcers. Transactions of the Royal Society of Tropical Medicine and Hygiene 80: 553-556, 1986.

12. Vera LA, Santos JB, Macêdo VO, Magalhães AV, Ciuffo IA, Santos CG. Avaliação da influência da infecção bacteriana secundária na evolução da leishmaniose cutânea em Corte de Pedra, Bahia. Revista da Sociedade Brasileira de Medicina Tropical 34:233-237, 2001. 